\title{
The Relation between Consciousness and Emotions in the Thought of Karol Wojtyła
}

\begin{abstract}
This article presents Karol Wojtyła's thinking on consciousness and its possible distortion called the 'emotionalization of consciousness'. In consciousness two functions can be distinguished, namely a receptive function and an experiencing/ interiorizing function. When the emotionalization of this dual structure takes place, consciousness is weakened in registering emotional facts (in their cognitive aspect) as well as in their proper experiencing (i.e. in referring them to the interiority of the subject). Wojtyła concentrates on self-knowledge as a power, which can contribute to limiting or eliminating the emotionalization of consciousness. However, he does not mention how to strengthen self-knowledge and make it more adequate for the job. Hence, in the paper, the author underlines the role of understanding and command of language, which can make self-knowledge a more efficient tool.
\end{abstract}

\section{Keywords}

Karol Wojtyła; consciousness; emotions; emotionalization of consciousness; selfknowledge; language

\section{Introduction}

Dealing with emotions, especially when they are strong and seem to overwhelm us, is a real challenge. It becomes even harder when these emotions accompany a moment when we are to make an important decision. Then, we are forced to fight as if on two "front lines": first, to curb our emotions and second, to think logically with maximum precision in order to prepare the ground for an adequate decision. Over the centuries many thinkers and sages have given us various clues and strategies of how to win the day, that is, how to remain 
rational and steadfast versus irrational and strong emotions. Today, this topic is also often undertaken by many scholars, not only because of its importance in practical behavior but also because of its significance for the understanding of human nature. We are still interested in the sphere of reason and the sphere of emotions, and in the relationship between them.

The relation between the human intellect and emotions has been at the center of attention for many psychologists as well as philosophers for a long time. In the case of the former, the topic has been considered, for example, within a series of books written by Daniel Goleman and others, with the telling title "Emotional Intelligence" ${ }^{\prime \prime}$. In the latter, various philosophers ${ }^{2}$ including many phenomenologists ${ }^{3}$ entertained a vivid interest in the intersection of these two human powers. One of them was Karol Wojtyła (1920-2005). He mastered a great deal of phenomenology although his analyses on the human being cannot be entirely limited to this philosophical approach. He should be rather classified as a personalist. In his main work of philosophical anthropology, the Polish philosopher took up the relation between consciousness and emotions. Let us treat consciousness as one of the instantiantions of the intellect and reason. Wojtyła gives some scholarly attention to the influence of emotions on consciousness, and in doing so he is far from underestimating the positive role of the emotions in the life of the person. But he is also aware that at times emotions are able not only to modify positively (e.g. empower) the activity of consciousness but also to deform it. In this sense, they do not play a creative role in the scheme of personal existence and even interfere in personal fulfillment.

1 D. Goleman, Emotional Intelligence: Why It Can Matter More Than IQ, New York 2005; D. Goleman, Working with Emotional Intelligence, New York 2000; L. Lantieri, Building Emotional Intelligence: Practices to Cultivate Inner Strength in Children, Boulder 2008.

2 Many proposals have been put forward by various philosophers to determine this relation. Let us only point to one interesting example. Peter Goldie sees emotions strictly intertwined with reason. He claims that "feeling towards is thinking of with feeling, so that your emotional feelings are directed towards the object of your thought". P. Goldie, The Emotions. A Philosophical Exploration, Oxford 2000, p. 19. Generally literature in this respect is enormous. Let us mention several examples: G. Corradi Fiumara, The Mind's Affective Life. A Psychoanalytic and Philosophical Inquiry, Philadelphia 2001; G. F. Schueler, Desire. Its Role in Practical Reason and the Explanation of Action, Cambridge MA 1995; Thinking about Feelings. Contemporary Philosophers on Emotions, ed. R. C. Solomon, New York 2004.

E.g. M. Scheler, Formalism in Ethics and Non-Formal Ethics of Value. A New Attempt toward the Foundation of an Ethical Personalism, trans. M. S. Frings, R. L. Funk, Evanston 1973, p. 253-264. 
This topic will be the subject of our attention in this paper. We will also be concerned with possible remedies for this negative scenario.

\section{Consciousness Under the Influence of Emotions}

Wojtyła's understanding of consciousness is very original. He departs from the paradigmatic phenomenological stance at issue. Doing this he basically disagrees with the thesis that consciousness is an intentional power, let alone an autonomous subject. Wojtyła understands it as a passive, or at most, semiactive power, which is complex in itself and cooperates with knowledge and self-knowledge. Consciousness alone has two functions: first, it receives, and in a sense, mirrors ideas and information acquired by knowledge and selfknowledge. The latter are active powers, which are directed toward external, as well as internal objects. They also objectify cognitively these objects and make them into mental representations, which are subsequently delivered to the consciousness. Consciousness mirrors this input, which means it receives its content as such and makes it evident for the subject. This is a first step in the process of interiorizing and has rather a cognitive character. At the second stage, consciousness refers the received content to the inner circle of the self, namely the "I". This mode of operation is usually associated with a set of emotional experiences. It means that the received cognitive content referred to the "I" gets this or that emotional color or flavor, and helps the person in approaching her fullness (it is a kind of ontological coming to be or building up of the person) $)^{4}$.

Once it is completed the person possesses not only a new rational idea but it also has an emotional and subjective link with it. Moreover, the newly acquired object enriches the personal interiority - in a sense it expands the personal "I". The subject then can claim, for instance, that "I" do have it as my personal possession and it provides me with an additional space for self-expression. In this way we can spell out the aforementioned term "ontological building up of the person". When the whole process is uninterrupted, the emotional color of a given content is adequate to its significance and importance. However, this sequence of knowing and experiencing can be impaired or distorted. The

4 These two functions constitute a standard model of consciousness, and it will be referred to in this way in subsequent sections of the paper. 
Polish philosopher calls this event 'the emotionalization of consciousness'. In the next section we will turn to this issue. But first some light must be shed on a certain fundamental issue, the important of personalism as such.

Now we should delve into Wojtyła's general understanding of the relation between cognition and valuing, which is in some connection with our analyses. What is important here is that his stance is typical for a broader personalistic approach to the issue. A basic presupposition governing this relation is that there is not a sharp distinction between 'fact' and 'value', or more fundamentally - between 'being' and 'good's. Of course, they are not the same but also they are not alien or contrary to one another. However, having said that, we must acknowledge that we get acquainted with them and have access to them by various human powers and abilities. The mere content of a given fact or object is penetrated by an intentional power of knowledge (or self-knowledge), "whereas in an emotion we are reacting to a value which we find in that object"6. The Polish philosopher points out that these activities of knowledge and emotions complement each other and even are inseparable (we will elaborate on this later). Hence his explanation, "for we must take into account the fact that the different objects which we encounter in our sensory experience impinge on our attention not only as having content but as having value"

Let us assume that whenever we face an object of whatever kind, we acquire the data about it. But let us treat this data broadly, that is, including also a value aspect $^{8}$. Then we can divide that data into the data about facts, data-F, and the data about values, data-V. This distinction can help us in our subsequent analyses because consciousness has an active participation in this double registering of objects, including inner ones, that is, states and experiences taking place within the human person alone.

5 In a discussion on the priority of 'good' vs. 'value', or vice versa, the Polish philosopher puts the category of 'good' as a starting point. 'Value', engaging a subject and her experiences, is a way of carrying out the 'good'. See K. Wojtyła, Elementarz etyczny, Lublin 1999, p. 66.

6 K. Wojtyła, Love and Responsibility, trans. H. T. Willetts, San Francisco 1981, p. 102-103.

7 K. Wojtyła, Love and Responsibility, p. 103.

8 In a strict sense, the data stems from an empirical experience. In a broader sense, however, it also mirrors a moral experience. Of course, this broader grasp may not be widely accepted, especially by empirical philosophers. But for the present analyses - conducted within a personalistic stance - let us assume this dual structure, namely that the data is made up of an empirical facet as well as an axiological one. 


\section{Consciousness Overwhelmed by Emotions}

Karol Wojtyła considers emotions within his basic distinction, concerning all human activity, between happenings and acts. The latter engage the person in her full freedom and intentionality, whereas the former just take place in the human being. Emotions or emotional facts, as perceived by the Polish philosopher, have characters of happenings. Nevertheless, as such they are subjects to rational powers, including self-knowledge and consciousness ${ }^{9}$. They also influence these powers depending on various circumstances and factors. As far as consciousness is concerned, emotions play a role in reference to both of its functions. Emotions interfere in a mirror-like function as well as in an interiorizing one. In a basic scenario, consciousness and its accompanying powers keep control over emotions. This means that they are objectified by selfknowledge and, in a sense, put in front of the receptive consciousness and then interiorizing one. In this non-problematic scenario, the human being as a rational subject keeps a kind of distance from extra-rational factors. Additionally, the will also plays an essential role in exerting real control over emotions but we are not going to consider this aspect to a large extent in this paper.

The problem begins when consciousness loses its distance from emotional facts. The standard model of consciousness is then undergoing a kind of critical test. Wojtyła, as we mentioned above, calls this situation 'the emotionalization of consciousness'. It is usually connected with distortions of functions typical for subsequent stages of consciousness. Thus, self-knowledge is not able to grasp emotional facts in their meaning; the receptive, mirror-like consciousness does not mirror these facts as what they are; the interiorizing consciousness does not refer their content to the self of the person in an adequate way. This breaking down of the structure of consciousness is a direct result of the breaking down of self-knowledge. Its inability to grasp rationally the meaning of a given emotional fact brings about further stages of consciousness as dysfunctional and hence non-constructive for the person.

The center of the problem consists of the collapsing of self-knowledge. As Wojtyła put it, "the breaking down of the objective relation of consciousness to feelings, as they "are happening" in the human being (...), comes from the

9 In this sense, we cannot treat emotion as a kind of "surd" or an irrational event. Although it has its own source, for Wojtyła emotion or a whole sphere of emotions is in a relation to the mind, that is, it can be grasped by self-knowledge and mirrored by consciousness. I will elaborate on this topic below. 
fact that self-knowledge stops objectifying. It does not establish meaning and as a result, it does not hold emotions in intellectual dependency"10. We can ask why self-knowledge stops carrying out its vital function. The Polish philosopher offers two explanations. First, self-knowledge can be overwhelmed by a power of an ongoing emotional fact. This can be the case when external factors are so strong and compelling that they cause a state of shock in the human subject. Or the subject is oversensitive and prone to experience feelings very intensely and disproportionately. Second, self-knowledge is not competent enough to cope with emotional pressure and can easily undergo a kind of dysfunction.

Wojtyła claims that self-knowledge plays an essential role in the emotionalization of consciousness because only this cognitive power can be more or less developed in its activity. Consciousness itself - as he points out - can be, at most, more or less mature ${ }^{11}$. Self-knowledge is, then, the main factor responsible for objectifying any emotional facts. In a normal course of action (in the standard model of consciousness), a subject is in possession of cognitive premises and abilities to control them. Those emotional occurrences are made into known facts and so become adequate for the human being as a rational creature. Of course, it is not equivalent to full control over the emotions, because, as a philosopher put it, "emotions are somewhat recalcitrant to reason"12. Hence-as was mentioned above - real control over them cannot be exerted without the active engagement of the will ${ }^{13}$. Nevertheless, if we accept the presupposition that an act of the will must be adequately informed in order to initiate a typically human action (the act) toward a given fact, the process of objectifying of the fact is the first step in exerting real control over it. The above mentioned concept of "intellectual dependency" must be construed this way.

Now let us look at the process of the emotionalization of consciousness in some detail. It will help us to realize how the standard model of consciousness is made dysfunctional. Let us consider the influence of emotional facts on two

10 K. Wojtyła, Osoba i czyn, in K. Wojtyła, Osoba i czyn oraz inne studia antropologiczne, Lublin 1994, p. 102. The English edition of this book is The Acting Person, trans. A. Potocki, A-Th. Tymieniecka, Boston 1979. All quotations are taken from the Polish version and translated by the author of the paper.

11 This distinction is in fact discrimination between a fully active power of self-knowledge and a semi-active power of consciousness.

12 P. S. Greenspan, Emotions, Rationality, and Mind/Body, in Philosophy and the Emotions, ed. A. Hatzimoysis, Cambridge 2003, p. 115.

13 K. Wojtyła, Osoba i czyn, p. 102-103. 
essential functions of consciousness. When we take into account the receptive and mirror-like function, we realize that the pressure of emotional facts - which crosses a threshold typical for a mature and balanced individual - makes consciousness weaker in its natural role. It reflects those facts as something, which happens in a subject, but a link with the self is lost or substantially weakened. It is thus, because when a subject keeps control over emotions, she experiences them as her own feelings, as happenings belonging to herself and having a common ground in her being. In this way, the human being is able to discern both their cognitive unity and diversity: they have something in common with each other, but at the same time they differ. Thus, due to an existing link with a subject, emotional facts can somehow be identified. This advantage is lost once self-knowledge stops objectifying and grasping the particular meanings of those facts. They are mirrored by the first instance of consciousness but without cognitive control over them, that is without a full realization of what they are.

The second function of consciousness is also influenced by this process. As at the previous stage, we face the emotionalization of cognitive mirroring: thus at this stage we are before the emotionalization of experience. In other words, the emotionalization of experience concerns how the flow of strong emotions distorts the emotional reception of any given data breaking the natural rhythm of experiencing it. This results in a kind of emotional overpowering. Emotional facts function in the person semi-autonomously. In other words, there is a slight link between them and the subject. The person is the arena for them, however, her involvement in what is going on is minimal. Loss of control over emotions leads to experiencing them as raw and primitive facts. Wojtyła underlines that such emotional facts are experienced in a heteronomous and non-personal way ${ }^{14}$. It is, as if they were taking place next to the person but not in the person itself. We will elaborate more on this later on.

This is, of course, a situation which does not live up to the status of the person. In other words, the person participates in something, which is "below" her dignity. The Polish philosopher is convinced it is thus because any experience entertained by the human being, in order to live up to the requirements of personhood, must be unified with her to such an extent that it clearly contains the experience of her subjectivity. As Wojtyła points out, "adequate to the

14 K. Wojtyła, Osoba i czyn, p. 104. 


\section{The Person and the Challenges \\ 156 Volume 5 (2015) Number 2, p. 149-164}

person is this experience, within which the experience of the subjectivity of her own "I" can be marked out"15.

The emotionalization of experience is quite disadvantageous for the person and the person's life. Wojtyla observes that an "invasion of emotions" weakens the human subject because it loses some control over an essential set of feelings. It is like giving way to strong factors, which dominate not only the thinking but also the experience of personal integrity and identity. The philosopher is convinced that the "I" plays a central role in all acts of the subject, including the emotional ones, and the ordinary course of the subject's life revolve around that center ${ }^{16}$. It means that the "I" is not only a final destination of these various factors but also present in all of them. Hence - as we mentioned above-adequate experiencing of an emotional fact has as its constituent the experiencing of the subject. When the power of emotions is overwhelming, the "I" is put aside, and, so to speak, removed from the center of what is going on. She can only "observe" the set of happenings as if from outside. Wojtyła describes it in this way, "the human being (...) only lives with her emotions, allows them to live in her according to the measure of their primitive subjectivity. However, she does not live them out subjectively in such a way, that in this experience the personal "I", as the authentic center of experience, was highlighted"17.

Remarks presented by Wojtyła are based on the presupposition - mentioned above - that all experiences given to the person must be referred to the personal center of her being. Only then are they made into a real part of her life. Of course, questions arise in this context: are personally experienced emotions parts of personhood or personality? Or, in other words, do human beings become more mature persons or personalities after a series of properly experienced feelings? It seems that the Polish philosopher does not delve into such a distinction. He seems to adhere to the thesis that current experiences grasped by self-knowledge, the mirror-like and the experiencing/interiorizing consciousness lead to the fuller maturity of the whole interiority of the person (including her psyche, mind, conscience, etc.).

\footnotetext{
15 K. Wojtyła, Osoba i czyn, p. 104.

16 K. Wojtyła, Osoba i czyn, p. 104.

17 K. Wojtyła, Osoba i czyn, p. 104.
} 


\section{Self-knowledge in Its Operations}

The emotionalization of consciousness can be avoided in various ways. It can be a job for the psychologist who helps a given person to control her emotions. Consequently, it will be the task of that person to work on her emotions and not let them dominate her cognitive abilities. But Wojtyła, in dealing with the emotionalization of consciousness, goes the other way. He does not put the emphasis on the psychological side but rather on the philosophical one. He points to self-knowledge as a tool in preventing the emotionalization of consciousness scenario. It is worth mentioning that the discussion about self-knowledge has had a long tradition. It started in ancient philosophy but since the beginning of modern philosophy self-knowledge, its acquisition and its extent, has been keeping a special position in epistemological investigations. In contemporary philosophy it has different faces, including a discussion between the rationalistic and the empirical approach so as a more reliable tool of its acquisition ${ }^{18}$. However, we are not going in this direction with our analyses and hence we limit our analyses to a range of interest entertained by the Polish philosopher. Thus, let us now look closely at Wojtyła's understanding of self-knowledge in order to find some clues concerning how to make it stronger and more adequate.

Self-knowledge is the active power of the person. As we mentioned already, it embraces cognitively some essential elements like the person, her "I", her acts and actions, including emotional facts, consciousness of these acts as well as consciousness of the person herself, and makes them into objects of cognition. Self-knowledge accompanies the "I", made into an object of cognition, in all circumstances where it operates. As Wojtyła puts it, "self-knowledge centered on the own "I" as her proper object, goes with it into all domains in which this own "I" permeates"19. Self-knowledge carries out an objectification of these domains but not for the sake of themselves. It is done only for the sake of the own "I". Because the "I" is understood as multi-dimensional, the "regions" it can possibly enter are many. Consequently, self-knowledge acquires an opportunity to penetrate them and gain some data about them, but always the data with a strict reference to the "I". The Polish philosopher gives us some examples of such specific self-knowledge: moral self-knowledge, religious self-knowledge,

18 See e.g. B. Gertler, Self-knowledge, New York 2011.

19 K. Wojtyła, Osoba i czyn, p. 88. 
and social self-knowledge ${ }^{20}$. Following these examples, we can add additional variations, such as, scientific self-knowledge, cultural self-knowledge, and historical self-knowledge, to name only a few.

Wojtyła stresses the fact that self-knowledge aims at one's own, particular "I". This is the proper object of the cognitive power. However, the Polish philosopher is aware that self-knowledge remains the proper knowledge all the time. This means that it naturally tends to "work out" the integral picture of the person. It is not a power overwhelmed and limited by varieties of particulars taking place in the person. Self-knowledge always tends toward general concepts. Of course, such generalities concern this particular person and are basically known to her alone. Wojtyła gives us two examples of such generalities, pointing to the general view of self and a moral assessment of self. Self-knowledge is then equally concerned with a cognitive aspect of the "I" as well as with its axiological facet ${ }^{21}$. As we earlier noticed, the data-F always accompanies the data- $\mathrm{V}$ so, and at the end, they contribute to various aspects of a picture of the same person.

The Polish philosopher goes further with the characterization of selfknowledge. The person is the main object of this cognitive power, although the power itself draws upon the personal experiences of a given individual. As he puts it, "a whole cognitive work goes exclusively from self-experience to self-understanding" 22 . The person is first an object of experience and only later an object of knowledge. What is the role of general knowledge of the human being in this scheme? Wojtyła notices that there is a passage from an outer knowledge of the person to an inner knowledge. "Self-knowledge uses the knowledge about the human being, i.e. various views of the human being as well as the knowledge gained from experienced relationships with other people, in order to understand better her own 'I"'23. Nevertheless, this outer knowledge is, all the time, an additional and a helpful tool only. Self-knowledge is not directed toward the human being as such, but to this particular person: so any general understanding of the former plays its role only when it sheds some light on the latter.

\footnotetext{
${ }^{20}$ K. Wojtyła, Osoba i czyn, p. 88.

${ }^{21}$ K. Wojtyła, Osoba i czyn, p. 88-89.

22 K. Wojtyła, Osoba i czyn, p. 89.

23 K. Wojtyła, Osoba i czyn, p. 89.
} 


\section{Self-knowledge as the Guardian of Consciousness}

Wojtyła is aware that self-knowledge determines the boundaries of consciousness. As we pointed out above, consciousness is not an autonomous subject creating its own content. It is not an intentional power going out to things, including the person itself, and capturing new essences. Consciousness is exclusively "fueled" and "equipped" by knowledge and self-knowledge. This dependency leads to two consequences. First, self-knowledge establishes the boundary line for consciousness. The latter works exclusively on the data delivered by the former, including the data-F and the data-V. As Wojtyła observes, this fact helps to secure a realistic profile of consciousness: it is always centered on the 'being' (and the 'good') ${ }^{24}$. In other words, consciousness is not left alone as a 'producer' of its own content. Second, however, consciousness can be easily deformed by a wrongly operating self-knowledge. And this is the case in the emotionalization of consciousness. Thus self-knowledge plays quite a fundamental and essential role. Strengthening it and making more adequate can substantially strengthen the person in her vital operations.

It seems that there are two ways of doing this: the first we can call "internal", and the second - "external". The former concerns the "natural" path that selfknowledge follows. As mentioned already presenting the standard model of consciousness, it is directed to objectify the person and everything taking place in her. Looking chronologically, self-knowledge intentionally captures all acts of the person as well as happenings, including emotional facts. Then, it converts them into pieces of information (although value-laden), which are in turn delivered to the mirror-like consciousness. When that bit of information is received and "absorbed" by the second function of consciousness, namely the experiencing/interiorizing one, it is introduced into the circle of personal life - enriching and expanding it. But the result of this process is again made into a subject of self-knowledge. In other words, self-knowledge is concerned not only with the "input" but also with the "output" of consciousness. If it is thus, then it brings with it some important consequences.

Self-knowledge should become mature and more adequate by itself. Comparing the input with the output should be very instructive for its operations. The quality of the output of consciousness is vitally dependent on the quality of its input. Poor output should work as a stimulus for the whole cognitive power and should

${ }^{24}$ K. Wojtyła, Osoba i czyn, p. 86. 
result in a better approach to the process of acquiring knowledge, which, in turn, would lead to an improved quality of a new input. Self-knowledge should correct itself in order to be more efficient and in this way become enhanced by its very functions all the time. It also seems that self-knowledge has an "inbuilt" function of reflexivity, that is, it can make its own mode of operation into an object of cognition. Hence, this power can follow reflexively its own way of intentional going out to an object, its objectification and a final deliverance of the data to the threshold of consciousness. This, additionally, should be helpful in correcting and amending its manner of acquiring the data. But if self-knowledge does not improve itself by itself, or when this improvement is poor, what can we do?

We can observe, from time to time, that there are some individuals who do not improve substantially the level of their self-knowledge. At least, we can infer this from their external behavior. What can we propose in order to bring them some help? Can we suggest to be more introspective, more attentive to all acts and happenings taking place in their person, or maybe something else? The problem is how to improve the process of objectifying the facts and in this way to make it more acute, sharp and precise. The solution proposed here is to put an emphasis on the use of language ${ }^{25}$. Self-knowledge seems to be more efficient if it is able to name adequately captured internal objects. If a person possesses a large vocabulary and has a good understanding of it and also masters all the other aspects of language (i.e. grammar, practical usage), there is a greater chance to formulate just categories for various internal experiences. These categories, of course, include not only particular words but also whole expressions and even elaborated narratives, because emotional facts can be quite complex and not easy to express in simple propositions. A good command of language, as a whole structure, can bring with it the powerful help in the process of objectifying internal and subjective experiences. Powerlessness, or a lack of sophistication in this respect, results in imprecise or faulty data delivered to

25 This proposal can be a part of the stance called "the language-reality problem." It essentially deals with the dilemma as to whether or not we have access to objective knowledge about existing reality. What is important for our investigation is a conviction that "the expression language-reality problem is used on the assumption that there is no knowledge of essential importance for this problem which for various reasons cannot be expressed by means of language." See N. O. Bernsen, Knowledge. A Treatise on Our Cognitive Situation, trans. H. Vohtz, Odense 1978, p. 117. In the case of Karol Wojtyła we have language-reality realism (as opposed to language-reality idealism), namely a position advocating for a thesis that we do have objective knowledge concerning existing reality. 
the consciousness. At any rate, the internal data is of high quality and seems to be ready for further operations when it is adequately linguistically grasped.

The external way of improving self-knowledge hinges on acquiring knowledge in the various contexts and circumstances externally related to the "I". As we mentioned above, self-knowledge goes with the "I" to all domains and regions where the latter operates or is influenced. We pointed to various versions of self-knowledge as the result of the presence of the "I" in different contexts and dimensions. Thus the human subject can acquire some specific knowledge when entering into the sphere of morality, religion, social interactions, culture, scientific or historical circles. Cognitive familiarity with these domains can deliver specific insights and, connected with them, opportunities for the "I" to realize that it lives and develops in specific circumstances and is, to some extent, conditioned by external factors.

Of course, a mere study of these external domains can be done in a very objective way, that is, for the sake of acquiring pure knowledge. Hence something more is needed here, namely a steady attempt to refer this knowledge to the process of self-understanding. Only then can we not only realize various contexts of our existence but also perceive ourselves as if from outside ${ }^{26}$. This proposed attitude is a combination of being itself and looking at itself as if through the prism of otherness. As a result it leads to strengthening itself by a confrontation with that which is not itself. Assuming that the ' $I$ ' tends to a kind of self-preservation, we have always the same 'I' looking from a numerical point of view but a modified one looking from a qualitative point of view. A new knowledge modifies our 'self', the 'I' but does not change it substantially. At any rate, the more knowledge in these particular spheres and dimensions is learnt by the person and referred to herself (i.e. to her interiority), the more mature self-knowledge should be. Acquiring knowledge means, to a great extent, to learn a new specific language. Thus linguistic abilities can expand potentialities of self-knowledge from the outside but also, after a process of internalization, from inside ${ }^{27}$.

26 Even psychologists point in this direction claiming that looking at myself from an external perspective, that is, through someone else's eyes, can be a fruitful way of increasing my self-knowledge. See T. D. Wilson, E. W. Dunn, Self-knowledge: Its Limits, Value, and Potential for Improvement, "Annual Review of Psychology", vol. 55 (2004), p. 507ff.

27 In Wojtyła's works we can also find other clues about how to make self-knowledge stronger and more adequate. One of them concerns art and especially poetry. The Polish philosopher himself was a poet and appreciated a role of poetic language in naming the internal states experienced by 


\section{Conclusions}

The emotionalization of consciousness is a negative phenomenon for the person. Wojtyła describes such a scenario as a distortion of the process of human cognition. His attention in reversing the emotionalization of consciousness is directed to self-knowledge and its role in this process. At the same time he is aware that other powers must be actively employed, like a strong will, in order to contain the excessive influence of emotions on consciousness. He does not elaborate on this aspect, limiting his analyses to the intellectual factor in dealing with emotions. The term "intellectual dependency" concerning the relation between mind and emotions draws the line of his interests. At the same time it touches on the core of the problem of the emotionalization of consciousness. Wojtyła, following Aristotle, is convinced that the mind plays a major role in the life and activity of the human being. The person is foremost an animal rationale. As mentioned above, it does not mean that other powers, including emotions, are less important. Nevertheless, in order to live them out in a really human way they are to be put in strict relation to the mind.

Wojtyła's suggestion of how to avoid the emotionalization of consciousness arises then from the idea of the strengthening of rational powers. In his writings, however, we are put before the problem but not offered its solution. The only thing we are given is a direction of approach. Thanks to this we are prompted to further investigation and can exercise various strategies, which subsequently can become a part of a broader philosophical picture. At any rate, over the history of philosophy many thinkers and philosophers have offered various proposals and methods of improving self-knowledge because since Socrates ("know thyself") the issue has been at the center of attention.

Our proposal supplementing this lack is a turn toward language. It indeed plays an essential role in acquiring new knowledge, including self-knowledge. Thus three aspects of the theory of language seem to be important for our investigation: sematic, syntactic and pragmatic one. An ability to name properly the internal states of the person hinges on a wide knowledge and good understanding of vocabulary, grammar and a practical usage of the language. Further elaboration on the struggle with the emotionalization of consciousness 
must show how a good mastery of these aspects of language can contribute to a positive outcome.

Philosophical studies on language are very advanced and complex. Here we cannot delve into the huge body of literature concerning this field. Let us point to at least one direction of further analyses. We can reflect on some basic understandings of the aspects of language taking into account their selected definitions. Following Mark Platts, a task of semantics can be presented in the following way: "A theory of meaning for a language should be able to tell us the meaning of the words and sentences which comprise that language" 28 . Or we can define it (as it was traditionally done) as an area "concerned with certain relations between words and the world", where the category of truth plays an important role. Pragmatics we can sketch as Donald Kalish did: "The study of properties of words which depend on their having been spoken, or reacted to, in a certain way, or in certain conditions, or in the way, or conditions, they were" 29 . These selected definitions are made up of elements (meaning, properties, relation between words and the world, the truth), which make parts of contemporary philosophical debates; in a sense they are at the heart of contemporary philosophy. If language is to strengthen self-knowledge, we must take into account all of these particular issues in two important areas. Because consciousness is concerned both with the data-F and the data- $\mathrm{V}$, the work on language should be pursued simultaneously in two fields: epistemological and ethical.

Thus we can present two final conclusions. First, a real attempt at improving self-knowledge sends us back to theoretical philosophy. An increasing awareness on how language works, in various dimensions, can bring us great help in knowing ourselves better. Second, working on self-knowledge leads the person from her interiority to exteriority: to the encounter with objects, persons, and ideas worked out in inter-subjective exchanges; and only then back again. Generally, the "I" who encountered and passed through "alien fields" has a greater chance to discover and sustain her identity, namely that among other existing things and elements I am a separate entity but, at the same time, I am in some relation to them and can understand myself better only with their help. In particular, this identity depends on such factors as ideas, reasons, emotions and values.

28 Ch. Travis, Pragmatics, in A Companion to the Philosophy of Language, eds. B. Hale, C. Wright, Oxford 1997, p. 87.

29 Ch. Travis, Pragmatics, p. 87. 
They must interact among themselves in an ordered and harmonious manner. It is only a case when we exclude extreme dominance and the disproportional role each of them can possibly play. Hence, struggle with the emotionalization of consciousness is a really vital task.

\section{Bibliography}

Bernsen N. O., Knowledge. A Treatise on Our Cognitive Situation, trans. H. Vohtz, Odense 1978.

Corradi F. G., The Mind's Affective Life. A Psychoanalytic and Philosophical Inquiry, Philadelphia 2001.

Gertler B., Self-knowledge, New York 2011.

Goldie P., The Emotions. A Philosophical Exploration, Oxford 2000.

Goleman D., Emotional Intelligence: Why It Can Matter More Than IQ, New York 2005.

Goleman D., Working with Emotional Intelligence, New York 2000.

Greenspan P. S., Emotions, Rationality, and Mind/Body, in Philosophy and the Emotions, ed. A. Hatzimoysis, Cambridge 2003, p. 113-125.

Lantieri L., Building Emotional Intelligence: Practices to Cultivate Inner Strength in Children, Boulder 2008.

Scheler M., Formalism in Ethics and Non-Formal Ethics of Value. A New Attempt toward the Foundation of an Ethical Personalism, trans. M. S. Frings, R. L. Funk, Evanston 1973.

Schueler G. F., Desire. Its Role in Practical Reason and the Explanation of Action, Cambridge 1995.

Thinking about Feelings. Contemporary Philosophers on Emotions, ed. R. C. Solomon, New York 2004.

Travis Ch., Pragmatics, in A Companion to the Philosophy of Language, eds. B. Hale, C. Wright, Oxford 1997, p. 87-107.

Wilson T. D., Dunn E. W., Self-knowledge: Its Limits, Value, and Potential for Improvement, “Annual Review of Psychology” vol. 55 (2004), p. 493-518.

Wojtyła K., Elementarz etyczny, Lublin 1999.

Wojtyła K., Love and Responsibility, trans. H. T. Willetts, San Francisco 1981.

Wojtyła K., Osoba i czyn, in K. Wojtyła, Osoba i czyn oraz inne studia antropologiczne, Lublin 1994, p. 43-344. The English edition of this book is The Acting Person, trans. A. Potocki, A-Th. Tymieniecka, Boston 1979. 